\title{
La agricultura a las puertas de la ciudad: arren- datarios, pequeños propietarios y grandes chacareros.
}

\author{
Valeria Ciliberto ${ }^{1}$
}

Durante años la dimensión humana y social, vale decir histórica, del espacio fue un tema casi olvidado en los estudios sobre la pampa. A fuerza de disociar tiempo de espacio, la campaña bonaerense fue generalmente asimilada a un desierto inculto, uniforme y sin dinamismo propio.

Pese a que hace ya algunas décadas la historiografía redescubrió en el Río de la Plata un mundo social y productivamente heterogéneo, pocas investigaciones escapan a aquella polarizada interpretación que concebía al campo y a la ciudad como componentes antagónicos de una especie de economía dual tradicional/moderna.

A partir de los aportes de trabajos que presentan la dinámica rural complementariamente asociada de la urbana abordando temas tales como la producción agrícola o las estrategias de dominio del capital comercial, centramos nuestra investigación en el análisis de las interrelaciones generadas entre la ciudad y su campaña inmediata en el marco del proceso de crecimiento de la

\section{1-CONICET-UNMDP-GIHRR.}

El presente trabajo forma parte de la memoria de D.E.A. Entre la campagne et la ville: aspects sociodémographiques de la croissance suburbaine. Flores, 1815 - 1869, presentada en la École des Hautes Études en Sciences Sociales en octubre de 1998. Agradezco los comentarios del árbitro anónimo de la revista. 
población y de expansión de la producción que tiene lugar en Buenos Aires durante la primera mitad del siglo XIX.

Sabemos que durante este período de importantes transformaciones en los ámbitos de la producción, del régimen de propiedad y de la organización político - institucional, la población rural crece más rápidamente que la de la ciudad. Y que a diferencia de otros procesos de desarrollo urbano, el crecimiento de Buenos Aires no implica el despoblamiento de su entorno agrario sino el de otras regiones del interior, históricas áreas de expulsión.

En el presente trabajo abordamos uno de los aspectos de este desarrollo, ocupándonos específicamente del pequeño universo de chacras y quintas periurbanas especializadas en la agricultura cerealera/frutihortícola del abasto.

Nuestra idea es articular, a partir del estudio del Partido de Flores durante el período comprendido entre inicios del siglo XIX y la década de 1860, las características generales del proceso de poblamiento del oeste porteño con aquellas dinámicas ligadas al uso productivo de las tierras agrícolas geográficamente más cercanas a la capital.

Una serie de padrones correspondientes al área realizados entre 1815 y 1869 constituyen nuestras principales fuentes documentales. A estas listas nominativas y censos sumamos legajos testamentarios y otros documentos de origen fiscal y administrativo (como la Contribución Directa, Duplicados de Mensuras y Registros de Arrendamiento y Enfiteusis Ventas) ${ }^{2}$ para profundizar las tendencias generales de la evolución de la población e, indirectamente acercarnos a la trama de relaciones sociales y mercantiles que este proceso teje en torno al crecimiento de las chacras y quintas.

Nos hemos centrado, entonces, en el análisis de un reducido contexto ensayando vincular aquella diversidad de actividades productivas, explotaciones agrarias y actores sociales de la que daba cuenta la renovación historiográfica no sólo con las particularidades de los ecosistemas o la antigüedad de asentamiento sino también con los clivajes espaciales expresados en términos de relación con el mercado.

\section{El mundo suburbano de las chacras y quintas}

En el marco de un persistente proceso de incremento demográfico y de

2-Los padrones del Partido de San José de Flores de los años 1815, 1836 y 1838 se encuentran en el Archivo General de la Nación (AGN), Sala X, 8-10-4, 25-2-4 y 25-6-2 respectivamente. El resumen de empadronamiento de 1854 en Maeso, J. (Ed.), 1855. Y el Primer Censo de la República Argentina, verificado los días 15, 16 y 17 de setiembre de $1869,1872$. 
expansión de la producción agropecuaria, el Partido de San José de Flores se configura, desde sus inicios, como un espacio cerealero pero sobre todo frutihortícola cuya producción alimenta el rápido crecimiento de Buenos Aires.

Sin embargo, este pueblo de chacras y quintas recostadas sobre el viejo camino a Potosí próspero ya desde los primeros años del siglo XIX recién comienza a transformarse casi seis décadas después, cuando el avance de lo urbano hace todavía más difuso el nunca claro límite entre el campo y la ciudad.

A través de los padrones podemos entrever cómo en torno a la propiedad de Flores, al oeste del puerto y sólo un poco más allá del ejido, miles de pequeños labradores y un grupo más reducido de importantes personajes porteños crearon con su trabajo e inversiones un mundo productiva, social y espacialmente diferenciado del urbano.

De este universo de extramuros, de chacras y quintas, hornos ladrilleros y potreros de alfalfa de las primeras décadas del siglo XIX conservamos bastante pocas imágenes, algunas litografías de artistas locales interesados en plasmar la vida cotidiana de los porteños y las impresiones de ciertos viajeros franceses o ingleses asombrados por la vertiginosa expansión del cinturón agrícola que alimentaba a la "gran aldea".

Nuestras fuentes sólo nos permiten intuir los cambios que ese crecimiento introdujo en la producción y en el paisaje de San José de Flores. Por las "miradas" contemporáneas sabemos que la producción de frutas y verduras ganaba espacio frente a la cerealera, aunque las sucesiones nos muestran que el trigo nunca desapareció del todo: chacareros y quinteros (en especial éstos últimos) combinaban ambas actividades.

Y la cantidad de trámites de mensuras de terrenos iniciados por los vecinos del partido en estos años nos sugiere que esa lenta reconversión hortícola supuso no sólo la multiplicación del cercado y el fraccionamiento de las propiedades sino también la ocupación de nuevas tierras (incluso de las inundables parcelas del bañado) y una mayor difusión del arriendo3.

Sin embargo, sabemos algo más sobre la fisonomía del Flores de la época a partir del censo de 1836, verdadera radiografía de los cinco cuarteles del partido que nos permite reconstruir la distribución espacial de sus chacras y quintas e hipotetizar sobre sus posibles articulaciones.

3-El 32\% de los escasos 25 Duplicados de Mensuras correspondientes al Partido de San José de Flores que hemos podido hallar en la Dirección de Geodesia del Ministerio de Obras Públicas de la Provincia de Buenos Aires, fueron presentados ante el Departamento Topográfico durante la primera mitad del siglo XIX. Y en casi todos estos expedientes figura con bastante detalle la lista de "los arrendatarios y pobladores que se expresan dentro de los limites de dichos campos". 
De modo que gracias a un gobierno más preocupado por contar las riquezas que las personas, conocemos el tipo de establecimiento tenido en propiedad por 303 de los 599 titulares de unidad censal empadronados (el 50,8\%).

Y muy de acuerdo con el perfil sociodemográfico de los habitantes del partido, sólo encontramos entre los "propietarios dueños de casas, estancias, chacras ó quintas" residentes en el pueblo y en los cuarteles de campaña a agricultores $^{4}$. Tendremos que esperar algunas décadas más para que varios "ganaderos" (muchas más veces invernadores que criadores) se sumen a Don Antonio Pereyra el único vecino censado al frente de una estancia.

Una lectura cuidadosa del cuadro I puede ayudarnos a esbozar un imaginario plano catastral del partido que complete aquel que el Juez de Paz Martín Farias presentaba seis años antes a la Comisión de Solares encargada de la nueva traza del pueblo.

El mapa mostraría a las 168 quintas contabilizadas repartidas equilibradamente entre los cuarteles segundo, tercero y quinto apareciendo en ellos como casi el único tipo de explotación, mientras que concentraría a prácticamente todas las chacras y a buena parte de las casas en el pueblo.

Al parecer las quintas a las que suponíamos más orientadas hacia los forrajes y la frutihortícultura se encontraban más cerca de Buenos Aires que las chacras dedicadas también al trigo. Y es que cuando la producción tenía que ser llevada diariamente a las plazas de mercado reducir, aunque sea unas pocas leguas, las distancias que las carretas tenían que recorrer debió ser esencial.

En realidad, demasiado apresuradamente asociamos a las quintas con aqueIla imagen resultante de la renovación de la historia rural, modestos productores que, prescindiendo de mercaderes intermediarios y valorizando el trabajo de su familia, participaban activamente en el abasto del mercado. Y convertimos a todas las chacras en los grandes establecimientos de "pan llevar" propiedad de agricultores capitalizados o de comerciantes de la ciudad, propias de la historiografía tradicional.

Sabemos que no fue necesariamente así, la diversidad de situaciones y actores sociales (desde el agricultor medianamente capitalizado hasta las familias que cultivaban reducidas parcelas) escondidos detrás de la categoría

4-Resulta difícil imaginar para esta época una marcada diferenciación entre el cuartel supuestamente "urbano" y los denominados de campaña. Para el año del censo encontramos un pueblo de chacras (solamente el 16,4\% -48- de las 292 propiedades registradas en este cuartel son casas) que nuclea al $47,2 \%$ de la población del partido ( 2.043 personas). Anteriores relatos de viajeros y fuentes oficiales nos lo describen como un espacio menos rural que el resto, punto de concentración y comercialización de los granos y ganados que, desde distintos puntos de la región, convergían en el abasto de Buenos Aires. Parchappe, N., 1977. Beaumont, J.B., $1957: 235$. 
labrador nos lo recuerda ${ }^{5}$.

Pero de hecho si bien algunas chacras se parecían a ciertas quintas (muchos inventarios emplean indistintamente ambos términos para referirse al mismo establecimiento) aparentemente Vicente Zavala -el Alcalde a quien le debemos el censo del partido- no tuvo mayores problemas al momento de diferenciarlas. Y probablemente nosotros tampoco los tendríamos si el padrón nos mostrara la compleja trama de relaciones entabladas al interior de las unidades censales...

De todas maneras, es bastante lo que de esas realidades domésticas podemos inferir relacionando la actividad preponderante de cada explotación (resumida en la denominación privilegiada por el empadronador) y la cantidad de personas registradas en las mismas. Así, si atendemos al tamaño de las unidades censales advertimos que las más grandes se concentran precisamente en el cuartel primero: son las chacras y, significativamente, las dos panaderías del pueblo las que cuentan con el mayor número de "blancos", "pardos y negros" y "extranjeros". (Cuadro II)

Sabemos que, ya hacia fines del siglo XVIII, los dueños de panaderías conformaban un grupo económicamente poderoso que concentraba las cosechas de trigo (comprando la directamente o a través de mercachifles rurales) y monopolizaba la molienda ${ }^{6}$. Y al parecer no dejan de fortalecerse, las unidades censales de los dos únicos panaderos del partido, Carlos Naon y Domingo Olivera, con 33 y 39 personas a las que suponemos trabajando en la cuadra nos hablan por sí solas de la relativa pujanza de esta actividad.

En contraposición, solamente 31 chacareros (el 40,8\% de los mismos) disponían de 9 o más personas para, imaginamos, trabajar sus sementeras; el $59,2 \%$ restante encabezaba UC que no superaban las 8 personas. De este modo no es extraño constatar que más de la mitad de la población conformaba unidades censales de entre 3 y 9 miembros (2673 personas), y todo parece más claro si agregamos que entre las mucho más numerosas quintas aquel porcentaje que calculábamos para las chacras se reduce al 33,5\%: únicamente 56 UC de este tipo comprende a más de 9 individuos, nuestros quinteros convivían en un $43,4 \%$ de los casos con entre 5 y 8 personas.

Evidentemente, aunque hallamos unidades censales comparativamente bastante populosas7, la mayor parte de las quintas y también de las chacras están

5-Remitimos al respecto a Ciliberto, M. V., $1999: 41-76$.

6-Garavaglia, J.C., 1991 : 11.

7-En Lobos la supremacía de la agricultura familiar se traduce en el predominio de unidades censales más pequeñas. De acuerdo con el censo del partido del mismo año, aquellas unidades productivas de más de 10 miembros representan al $16,9 \%$ del total de las mismas (87 sobre 427 ). E incluso en un área de vocación más ganadera que agrícola como era el partido de Quilmes en la década de 1830, este porcentaje se reduce al 10,3\% (67 de 648). Mateo, J., 1993 : 174. Santilli, D., 1996. 
lejos de parecer grandes unidades de producción basadas en el trabajo asalariado de peones y jornaleros. En realidad, más de la mitad de las explotaciones que el empadronador insiste en mostrarnos como unidades de propiedad recuerdan mucho a las de aquellos labradores que cultivaban la tierra auxiliados casi exclusivamente por los miembros de su familia más cercana.

Pero si bien entre estos supuestos pequeños productores propietarios los quinteros se perfilan como más modestos que los chacareros, ni los unos ni los otros constituyen grupos homogéneos a los que podamos atribuir características fijas. Y no es casual que encontremos la mayor diversidad de situaciones al interior de los establecimientos de chacra.

Señalemos muy brevemente que hacia los primeros años independientes (padrón de 1815) un número bastante reducido de chacareros había iniciado, y en algunos casos consolidado, un cierto proceso de acumulación. Ahora el censo inmediatamente posterior parece mostrarnos, a través de aquel 40,7\% de UC con más de 9 miembros, el crecimiento y fortalecimiento de este grupo. Sin dudas, la aparente magnitud y complejidad interna de sus unidades de producción nos confirma que la brecha entre estos agricultores y la mayoría de los campesinos chacareros no hacía más que incrementarse.

Obviamente, entre los propietarios de las "grandes chacras" de Flores no contamos al más capitalizado de ellos, el Estado. Ubicada en el cuartel tercero La Chacarita de los Colegiales, una extensa propiedad de 2700 varas de frente por una legua de fondo otorgada en merced a los padres jesuitas por el mismo Hernandarias (ampliada luego con compras y, sobre todo, donaciones) y ahora tierra fiscal constituía uno de los establecimiento productivos más importantes de los alrededores de la ciudad.

Hacia 1830 hallamos encargado de su administración a Don Anselmo Farias, destacado vecino federal del partido, quien seis años más tarde figura como titular de una de las dos unidades censales de la hacienda. En este caso, entonces, podemos estar seguros que tanto los 52 blancos, 7 pardos y negros y 1 extranjero registrados junto a Farias como los restantes "Indios y tropas de la Chacarita" (unidad independiente conformada por 3 blancos, 38 negros y pardos y 3 "tropa") se ocupaban de la cosecha y la molienda del cereal, dedicando también parte de su tiempo al trabajo en el obraje textil y en los hornos de ladrillos de esta diversificada "empresa agrícola".

Sabemos que habitualmente la chacra aseguraba las fanegas de trigo que destinaba al consumo y al mercado asumiendo los costos y riesgos de la puesta en producción directa de sólo una parte de sus tierras y arrendando el resto a distintos labradores por un canon en semillas ${ }^{8}$.

8-Fradkin, R., 1992 : 67-92. 
La agricultura a las puertas de la ciudad...

De modo que, sin contar a algunos cuantos peones y jornaleros más o menos permanentes contratados directamente por Farias muchas de esas 53 personas consideradas blancas por el Alcalde del partido formaban parte del cada vez más numeroso grupo de arrendatarios que, desde varias décadas atrás, había comenzado a desplazar a los indios y esclavos africanos (fuerza de trabajo tradicional de las haciendas jesuitas rioplatenses).

Y podemos suponer que varios de entre ellos se parecerían a Don Clemente Miranda quien, desde 1823, cultivaba la Chacra del Colegio pagando por ella un bastante elevado canon de 400 pesos anuales. Aunque otros, tal vez muchos más, atravesarían por una situación similar a la de Manuel Silva arrendatario de tan sólo tres cuadras cuadradas de terreno, que recién en 1826 podía reglar su deuda de seis años de pagos atrasados entregando a la Contaduría la suma correspondiente a 24 pesos ... ${ }^{9}$

Sin embargo, historias como la de Miranda no parecen haber sido muy singulares $y$, de hecho, hacia la tercera década del siglo la prosperidad parece haber alcanzado a buena parte de los más antiguos agricultores arrendatarios de las tierras "que fueron de los Jesuitas". Y basta que consultemos la sección Ventas del mismo Registro para advertir que muchos de sus apellidos figuran entre los de los nuevos propietarios de La Chacarita.

Pero si en algunos casos se trata de auténticos arrendatarios capitalizados gracias al desarrollo de una agricultura intensiva y mercantilizada, muchas de estas repentinas pequeñas y grandes fortunas parecen ligadas a los vaivenes políticos de una época convulsionada por el enfrentamiento entre unitarios y federales. Así, 56 de las 59 operaciones de compra y venta de los terrenos de esta chacra cerealera fueron efectuadas entre junio y diciembre de 1836, inmediatamente después que por ley se autorizara al gobierno rosista a vender 1.500 leguas de aquellas tierras dadas en enfiteusis o que aún permanecían baldías.

Evidentemente, parece de más acotar que poca tierra de quintas baldía quedaba en Flores, que el sistema de enfiteusis afectó únicamente a 0,0043 leguas del partido ${ }^{10}$ y que a varios de estos compradores los volvemos a encontrar en la lista de los federales, por supuesto, más adictos al Restaurador.

De este tipo de supuestos "premios encubiertos" surgirán conflictos tan curiosos como el que protagonizaron los herederos de Don Manuel Isidro de la Sota y los albaceas testamentarios de Don Manuel Antonio de Oya Benavides,

9-Contaduría General de Arrendamientos, Registro de Arrendamientos y Enfiteusis Ventas, 1818-1838, Partido de San José de Flores. Dirección de Geodesia, Departamento Investigación Histórica y Cartografía, Ministerio de Obras Públicas de la Provincia de Buenos Aires.

10-Coni, E., 1927. 
ejemplo que puede ayudarnos a conocer algunas de las estrategias que hicieron de estos campesinos arrendatarios prósperos chacareros propietarios.

De la Sota había comprado "al Supremo Gobierno de esta Provincia una chacra situada en la Chacarita de los Colegiales ... cuya extensión se compone de veinte y seis cuadras cuadradas, mas cuarenta y nueve centésimos de otra ... siendo prevención que el hedificio y parte del Monte y arboleda que se halla en dicho terreno es perteneciente a la testamentaria del finado Benavides, por haber construido en tiempo que el poseía en Enfiteusis la mencionada chacra...". De acuerdo con la viuda su "finado esposo era propietario directo del fundo y Oya solo era señor del dominio útil..." (Subrayado del original)

Al parecer, un inestable contexto político-institucional y derechos poco claros de propiedad dieron a De la Sota la oportunidad de iniciar un proceso de capitalización bastante exitoso que le permitió legar a su familia no sólo la chacra de Flores valuada en 36.750 pesos moneda corriente sino, además, una casa en la ciudad".

Sin embargo, la estrategia inversa (es decir aquella que afirmaba un derecho pleno de propiedad) también conducía a los mismos resultados como parece mostrarlo la experiencia de Don Bernabé Bojorge otro de nuestros flamantes propietarios, quien una vez adquirida la "... valiosa quinta de 9 cuadras de terreno...", se apresuró a ponerla en producción y a instalar junto a árboles frutales y alfalfares una pulpería, rentables negocios que convirtieron a nuestro pulpero-quintero en un importante inversionista urbano ${ }^{12}$.

$Y$ encontramos decenas de estos labradores "inquilinos" capitalizados poblando las grandes chacras de Flores que, como sabemos, no eran patrimonio exclusivo de las instituciones eclesiásticas. A medida que avanzamos en el siglo XIX cada vez son más los agricultores propietarios que recurren a la asociación producción directa-arrendamiento para ampliar sus stocks comercializables, asegurar -aún en los años de malas cosechas- su participación en el mercado de abasto triguero o simplemente contar con un ingreso estable en forma de renta que podía ser reinvertido en sus establecimientos o en cualquier otra lucrativa empresa.

Muchos otros, en cambio, prefirieron fragmentar sus terrenos en quintas de reducidas dimensiones y arrendarlas por separado. De esta manera evitaban los costos del mantenimiento y mejora de sus montes de árboles y edificios, valorizaban las peores tierra de sus propiedades (aquellas afectadas por las creci- 
das del río por ejemplo) y, en algunos casos, hasta se abastecían por fuera del mercado de las frutas y verduras que diariamente consumían ${ }^{13}$.

Podemos acercarnos a lo que aparentemente fue un modo habitual de implementar esta lógica a través del ejemplo de uno de nuestros panaderos, Carlos Naon dueño además de la quinta del "Caballito". Esta propiedad de 87.043 varas cuadradas "... dividida en cuatro quintas independientes, dos con edificio de material uno de gran valor (la esquina o estación del Caballito)..." se encontraba arrendada a José Naon y Miguel Deberó por 200 y 400 pesos mensuales respectivamente. Además de estos, por cierto deudores, inquilinos un grupo de italianos de "oficio quintero" ocupaban los fondos de la quinta "... sobre el ferrocarril ..." pagando por ello, a juzgar por los 480 pesos que Antonio Peruzzi adeuda a los herederos, cánones similares.

Pero el Concurso de la Testamentaría de Naon, que culminará con el remate de la quinta y su partición en 6 pequeños lotes, nos muestra algo más que los incumplidos compromisos de sus arrendatarios. Por la detallada lista de acreedores descubrimos que éste debía a Juan Martín de Estrada 6 años de alquiler de un terreno que desde 1855 arrendaba por 1500 pesos anuales... Nuestro panadero -propietario -arrendador era también un agricultor-arrendatario ${ }^{14}$.

Por supuesto que historias como las de Naon no eran la generalidad, el arriendo fue para gran parte de los quinteros del partido un más que conveniente negocio e, incluso, representó para unos cuantos de éstos la única estrategia "productiva" sino posible por lo menos ensayada. Nos referimos a aquellos que, aunque no eran vecinos de Flores, igual fueron registrados en el censo de 1836 por un Alcalde interesado en no dejar escapar a ningún "dueño propietario".

Así, 28 propietarios residentes en la ciudad, entre los que encontramos a varios apellidos resonantes del comercio, el clero y la política local, figuran como titulares del $16,6 \%$ de las quintas que son, por otra parte, las únicas explotaciones de "dueños ausentistas" no institucionales.

Si volvemos a nuestro imaginario plano catastral e intentamos ubicarlos espacialmente, advertimos que la mitad de estos establecimientos se concentran en el cuartel tercero, al que suponíamos más próximo a Buenos Aires, donde alcanzan a representar al 34,1\% del total de sus quintas (14 de 41).

Aunque algunas de estas propiedades posiblemente fueron casas de veraneo de capitalinos acomodados, las más de las mismas parecen unidades productivas explotadas por arrendatarios. En ellas encontramos a 124 personas

13-Frecuentemente los contratos de arrendamiento de quintas incluían entre las obligaciones de los arrendatarios la de suministrar gratuitamente parte de lo producido al propietario. Fradkin, R., 1999: 26.

14-AGN, Sucesión $N^{\circ} 7213$ (Año 1861). 
"blancas" que, junto a bastante menos "negros y pardos" (40) y muy pocos "extranjeros" (19), conformaban unidades censales de 6,5 miembros promedio. De este modo, no parece absurdo pensar que muchos de estos pobladores a los que suponemos arrendatarios cultivaban sus quintas bajo condiciones similares a las estipuladas entre Don Simón Pereyra -uno de estos propietariosy sus inquilinos. Este conocido saladerista había invertido parte de las ganancias de su próspera empresa en la compra de varios establecimientos rurales de las cercanías de Buenos Aires entre las que se contaban las dos quintas de Flores.

Al igual que sus chácaras de Quilmes y de Morón, Pereyra arrendaba estas propiedades por un canon anual bastante elevado a los 6 blancos que el censista registraba habitando las dos unidades del cuartel segundo. Pero lo más interesante para nosotros son las disposiciones complementarias de los contratos a través de las cuales podemos entrever parte de las estrategias puestas en juego por este tipo de propietario. De acuerdo con estas cláusulas sus arrendatarios se comprometían, además de pagar el alquiler "en pesos moneda corriente al fin de cada año", a "... componer la casa, conservar los sanjeados, reponer los postes de durazno y entregar los animales vacunos con la marca de la casa y amansados para bueyes...". Por supuesto que las mejoras quedaban en beneficio del propietario ${ }^{15}$.

Evidentemente, el arriendo permitía a Pereyra no sólo preservar sino incluso incrementar su capital fijo sin nuevas inversiones ni gastos de mantenimiento. El trabajo de los arrendatarios valorizaba las quintas y aseguraba su futura producción, al tiempo que proporcionaba una entrada fija independiente de los rendimientos y evitaba la instalación de conflictivos pobladores ocasionalmente convertidos en quinteros (y los costosos pleitos judiciales de su desalojo).

Para algunos un medio de vincularse con la agricultura suburbana del abasto y consolidar ya importantes fortunas sin por ello descuidar sus principales actividades empresariales, para otros el camino hacia la capitalización y la propiedad, no es para nada extraño, entonces, la importante difusión de la práctica del arriendo entre las quintas de Flores.

Sin embargo, no solamente encontramos propietarios arrendadores entre los quinteros, sabemos que también algunos de nuestros grandes chacareros fragmentaron sus propiedades en parcelas de más pequeñas dimensiones y apostaron al arrendamiento como estrategia destinada a reforzar la inserción mercantil de sus establecimientos. $Y$ entre estos agricultores encontramos a ciertos 
productores cuyos patrones de inversión se asemejan bastante a los de aquellos personajes urbanos propietarios de quintas suburbanas. Don Domingo Olivera representa muy acabadamente a este grupo de empresarios rurales que conjugando producción y arrendamiento consolidaron un enorme patrimonio.

Sabemos que varios labradores arrendatarios sembraban alfalfa en la chacra de 11 cuadras cuadradas que Olivera poseía en el cuartel quinto de Flores, mientras que muy cerca de allí en su principal propiedad, la Chacra de los Remedios, los peones y jornaleros ocupados del trigo y las ovejas se alternaban con otros más numerosos agricultores (¿y pastores?) inquilinos. Y probablemente eran estos últimos los que usufructuaban los potreros situados "calle por medio al norte" de los que también era dueño Olivera.

Pero este múltiple propietario no solo recurría a las relaciones de arriendo y medieria para explotar sus chacras y alfalfares de las inmediaciones de la ciudad: tanto en su estancia de Luján como en sus campos del Paraje "El Potrillo" y de "Keken Grande" encontramos puesteros pagando canon. Porque tenemos que agregar que, aunque el valor de "Nuestra Señora de los Remedios" superaba, y en mucho, al de varias estancias de la época y la otra "pequeña" explotación era tasada en unos 78.630 pesos, las chacras, corrales y potreros que Olivera poseía en Flores no alcanzaban a representar ni el $8 \%$ de su patrimonio... ${ }^{16}$ (Cuadro III)

De modo que podríamos decir que el arrendamiento posibilitó dos situaciones aparentemente contradictorias: por un lado, el mantenimiento de las grandes chacras trigueras del partido mediante su interno fraccionamiento en varias unidades de producción y, por el otro, la multiplicación de quintas de más reducidas dimensiones pero de producción igual de intensiva y mercantilizada.

Así, la cada vez más amplia práctica del arriendo parece reforzar la presencia y continuidad de los pequeños y medianos labradores que pueblan nuestros padrones y censos. Suponemos que muchos de ellos encontraron en esta forma de tenencia la posibilidad de encarar las más especulativas y especializadas producciones con el único capital que poseían en abundancia, el trabajo de su familia, y en los convenios de no más de un año la flexibilidad necesaria para combinar estas actividades agrícolas con otras (complementarias o no) ligadas al abasto del mercado urbano.

De hecho, arriendo y movilidad ocupacional aparecen como complementariamente articulados e, incluso, por los ejemplos de prósperos agricultores arrendatarios convertidos en dueños de las tierras que alquilaban podríamos 
sumar a éstos un tercer componente y sugerir la combinación del arrendamiento con la pequeña propiedad.

En efecto, el censo de 1838 parece confirmarnos que arrendatarios y propietarios vecinos y no residentes continuaron siendo los principales protagonistas de la historia de ocupación y valorización de las tierras agroproductoras de los suburbios porteños. Los 533 nombres consignados por el juez de paz de turno son en sus propias palabras "... los de los dueños propietarios de chacras, quintas ó fincas, aún cuando muchos de ellos existen en la ciudad y los que la habitan son inquilinos o encargados de ellas".

Pero si confiamos en Martiner menos del $15 \%$ de los habitantes de Flores habían accedido a la propiedad, y entre ellos encontramos únicamente a 124 de los chacareros y quinteros registrados como tales tan sólo dos años antes ${ }^{17}$. Sorprendentemente, los dueños de quintas muestran una mayor continuidad que los de chacras, constituyendo el $76,6 \%$ de las personas empadronadas en ambos censos y representando con sus 90 explotaciones a más de la mitad de las que efectivamente sabíamos que existían en el partido (168).

Sin descartar la posibilidad de un importante subregistro selectivo, estos porcentajes parecen mostrarnos aquella reconversión hortícola de la que hablábamos en pleno desarrollo y, al mismo tiempo, recordarnos la escasa distancia que separaba a los pequeños-medianos quinteros de sus pares chacareros aún cuando fueran propietarios.

Pese a ser pocos los propietarios que conocemos con nombre y apellido, sabemos que su número no deja de incrementarse: a medida que avanza el siglo XIX y el mercado inmobiliario rural muestra mayor dinamismo las cercanías de la capital figurará como una de las áreas con mayor cantidad de operaciones de compra-venta de terrenos ${ }^{18}$. Hacia 1854, de acuerdo con el Registro Estadístico del Estado de Buenos Aires, 274 de los 362 agricultores contabilizados en la jurisdicción eran propietarios (el 75,7\%).

Por el sesgo de las fuentes consultadas recién volvemos a encontrarnos con nuestros propietarios vecinos y citadinos en 1863, año en el que el gobierno porteño intenta regularizar el cobro del único impuesto directo del aparato impositivo provincial, la Contribución Directa.

Originalmente creado como un impuesto a "los capitales empleados en fincas y terrenos de particulares", dadas las dificultades para fijar su valuación (la administración no contaba ni con información segura sobre el valor de las

17-Recordemos que, a diferencia del anterior, el censo de 1838 no consigna el tipo de propiedad poseída por los empadronados.

18-Saguier, E., 1993 : 31. 
propiedades sujetas a tributación, ni con los medios para verificar las voluntarias declaraciones de los contribuyentes) la Contribución Directa, sin constituir estrictamente un impuesto territorial, se había transformado en una suerte de gravamen sobre la propiedad ${ }^{19}$.

La apertura en cada partido de una nómina detallando “... las propiedades situadas dentro de sus límites, expresando el nombre del propietario; la clase de propiedad, el área de las propiedades rurales, en leguas cuadradas o varas cuadradas; el precio de la tierra por legua; el valor de la propiedad y la cuota de contribución que le corresponde...", tenía por principal objetivo corregir esta situación y aumentar las rentas producidas por esta fuente fiscal ${ }^{20}$.

De acuerdo con estas disposiciones, el Registro Catastral del Partido de San José de Flores ${ }^{21}$ contabiliza un total de 516 propietarios que conforman un grupo de lo más heterogéneo, abarcando desde dueños de "ranchos" con modestos capitales y exiguas extensiones hasta grandes hacendados chacareros de considerable fortuna.

Pero son los poseedores de "casa y quinta" los contribuyentes más numerosos, sus propiedades representan al 33,8\% del total de las mismas (180) superando, incluso, a las numerosas casas registradas en el pueblo y a los ranchos que, curiosamente, también pagaban esta tasa impositiva. Las 97 chacras, algunas casas de campo (39) y muy pocas quintas (14) completan nuestro cuadro de propiedades suburbanas. (Cuadro XIII)

Al parecer un mundo de propietarios rodeaba a la ciudad, si atendemos a la superficie del partido ocupada por estos "particulares" encontramos que 4 de las 5 leguas que, según el funcionario del Ministerio del Interior, comprendían el Flores de la época ya habían pasado a manos privadas.

$Y$, a juzgar por las extensiones medias registradas, este sería un universo en el que la presencia de pequeños propietarios no había dejado de ser importante. Las propiedades de superficies menores a las 22.500 varas cuadradas, lo

19-La ley del 12 de abril de 1839 afina los mecanismos de valuación de las propiedades imponibles, creando en cada distrito una Comisión Reguladora de Capitales compuesta por el Juez de Paz y los Alcaldes. Sin embargo, el carácter local de las mismas y la posibilidad de dirimir los posibles conflictos en torno a las tasaciones en una junta compuesta por el Juez de Paz más próximo, un contribuyente nombrado por el demandante, otro designado por el Juez y dos Alcaldes minimizaron los alcances reales de la nueva ley. Burgin, M., $1960: 251$.

20-El incremento de los gastos militares, particularmente en los años 1859-61, condujo a importantes déficits y a la inestabilidad financiera del gobierno porteño, obligado a recurrir a la emisión de papel moneda para cubrir sus deudas. Además, con el Pacto de Flores Buenos Aires no sólo se integró a la Confederación sino que también perdió el control sobre su principal fuente de ingresos, la aduana. Marichal, C., 1995 : 113.

21-Contribución Directa, 1863. 
que traducido en hectáreas serían poco más de una y media ${ }^{22}$, representan al $51,7 \%$ (275) de las 531 listadas por el Juez de Paz del partido y este porcentaje se eleva al 68\% (361) si incluimos a aquellas de hasta 7 hectáreas.

Sin embargo, relacionando su número con la cantidad de tierra tenida en propiedad descubrimos que los dueños de estas relativamente reducidas parcelas únicamente ocupan el 10\% (558,46 hectáreas) de la superficie total del partido que fijamos en 5703,8 hectáreas ${ }^{23}$.

En este segmento ubicamos junto a 118 de las 120 casas del pueblo, al $82 \%$ de las casas de campo (82) y a todos los ranchos, pero también a un porcentaje para nada despreciable de las casas quintas (20\%) y de las quintas $(28,5 \%)$. De hecho, las casas quintas no sólo constituyen el tipo de establecimiento productivo de mayor representatividad numérica sino que también aparecen como las explotaciones de más reducidas dimensiones con una media de superficie de 8,73 hectáreas.

De modo que nuevamente encontramos que sería su tamaño y, evidentemente, el capital invertido en ellas más que su producción lo que las diferenciaba de las quintas $y$, sobre todo, de las chacras. Porque, aunque el promedio de superficie de las quintas es ligeramente inferior al que calculábamos para las primeras ( $8,43 \mathrm{ha}$.), la mitad de estas explotaciones superaban en extensión las 7 hectáreas mientras que entre las chacras este mismo indicador alcanza las 40,9 ha.: únicamente 13 chacras contaban con menos de 90000 varas cuadradas.

Veamos como los capitales y cuotas reflejan estas disparidades. Pese a que, como advertía el gobierno al Juez de Paz, Flores contenía "... magníficas propiedades de recreo y es atravesado por un Ferro-Carril ... por cuya circunstancia los terrenos adyacentes han adquirido precios muy elevados", menos de la mitad de los vecinos empadronados contaban con capitales superiores a los 50.000 pesos (188 casos, el 35,4\%).

Si trazamos una línea imaginaria separando a los más ricos de los menos capitalizados aunque no pobres propietarios, descubrimos entre los primeros al

22-Recordemos que la legua equivalía a 6.000 varas, la vara a 0,866 metros y la legua cuadrada, hasta 1881, a 2.700 hectáreas. Transformamos las medidas en hectáreas mediante una operación relativamente simple: dividimos las varas cuadradas por 1.3334 (para pasar de un sistema hexadecimal a otro decimal) y este resultado lo dividimos a su vez por 10.000 para llegar a las hectáreas.

23-Los límites que establecemos entre pequeña, mediana y "gran" propiedad son, por supuesto, relativos al contexto de la estructura de la propiedad rural de la época. Sabemos que una superficie de 7 hectáreas definía a una explotación mixta agrícola-ganadera como pequeña y como muy pequeña a una estancia (la suerte de estancia rondaba entre las 1875 y 2025 ha.), pero no hemos encontrado ninguna precisión relativa a las tierras de agricultura cercanas a la ciudad. 
$33,3 \%$ de los chacareros mientras que confirmamos que más de la mitad de los quinteros y dueños de casas quintas ( 57 y $54,4 \%$ respectivamente) figuran entre los segundos.

En consecuencia, una mirada sobre las cuotas alcanza para constatar que el $68,7 \%$ de los 256 contribuyentes del partido que pagaban montos inferiores a los 600 pesos (un ciertamente elevado $48,2 \%$ sobre el total consignado) eran propietarios de "pobre condición social"24, es decir, de casas quintas. Y son también ellos los que conformando la "cantidad crecida de exceptuados" provocaban las quejas del jefe de la Oficina de la Contribución Directa.

Por supuesto que estas cifras y promedios no excluyen la posibilidad de encontrar entre las "casa y quinta" propiedades como la de Juan José Isaguirre con 225.000 varas cuadradas de superficie (16,86 ha.) y un capital de 120.000 pesos o entre las quintas algunas explotaciones de menos de una hectárea como la de Cabrera cuyo modesto capital lo eximió del pago de la cuota.

Por cierto que, si bien varias quintas se asemejan en extensión, capitales y cuotas a las más grandes casas quintas muy pocas se acercan a los que parecen ser los establecimientos más complejos y capitalizados de Flores, las chacras. Aunque deberíamos decir a un núcleo bastante reducido de chacras, aquellas cuyos propietarios concentran buena parte de las tierras del partido, poseen los más importantes capitales y, por supuesto, tributaban las más elevadas cuotas.

Estas 43 grandes chacras ocupaban, con extensiones promedios de 75,6 hectáreas, el $57 \%$ del territorio de Flores $(3251,6$ ha.) y el $83,6 \%$ de la superficie del total de estas explotaciones. Ninguno de sus dueños (que, por otra parte, son los mismos de siempre: Segurola, Olivera, Farias, Visillac...) declaraba un capital inferior a los 38.000 pesos y ellos solos aportaban el $18 \%$ del total de lo recaudado por la Hacienda mediante este impuesto. $Y$ es fácil sospechar, dadas las características de la fuente, que estos realmente ricos productores lo eran aún más...

En pocas palabras, la lista de la Contribución Directa parece mostrarnos algo que ya conocemos gracias al análisis demográfico de la población: algunos grandes productores propictarios conviviendo con muchos otros pequeños agricultores, ahora sabemos, también propietarios dedicados a las mismas actividades aunque obviamente diferenciados en cuanto a patrimonios

24-Así es definido por su albacea testamentario Don Regino Carreras, vecino de San José de Flores quien figura en la lista de la Contribución Directa como propietario de una casa y quinta de 22.500 varas cuadradas valuada en 30.000 pesos. Por su testamento sabemos que al momento de su muerte poseía “... una finca y terreno situados en la estación del Ferro Carril del Oeste denominados de Almagro, cuartel cuarto del Partido de San José de Flores ... y unos cuantos muebles." AGN, Sucesión N 5000 (Año 1870). 
y posibles estrategias de inversión.

La heterogeneidad de situaciones productivas y la diversidad de actores sociales involucrados en la agricultura del abasto urbano que encontramos desde inicios de siglo no hacen más que reproducirse en este más pequeño mundo de propietarios. La novedad parece ser, entonces, la continuidad.

\section{Algunas reflexiones finales}

Al parecer, las crecientes necesidades de abasto del mercado urbano orientaron los cambios agrarios de su campaña próxima, modificando el espacio productivo y la estructura social de su área de aprovisionamiento. El crecimiento de Buenos Aires, entonces, reguló y articuló las modalidades y los ritmos de desarrollo de su inmediato hinterland agroproductor.

Así, los chacareros, quinteros y mercaderes de nuestros censos y listas impositivas junto a los miles de porteños que habitaban la ciudad convirtieron al pueblo surgido de las tierras de los Flores en uno de los polos más dinámicos del crecimiento suburbano. Migrantes agricultores, propietarios, arrendatarios... la pluralidad de actores sociales del mundo extramuros de las chacras y quintas nos acerca a una de las grandes continuidad de este proceso de poblamiento y ocupación del espacio, las pequeñas y medianas unidades de producción basadas en el trabajo familiar.

Porque pese a la diversidad de la compleja trama de situaciones y relaciones que el mercado teje y desteje en torno al abasto, el paisaje productivo y social que los padrones y censos reflejan nunca dejó de ser el de pequeñas quintas y medianas chacras, cada vez más frutihortícolas que cerealeras, de labradores locales aunque también de inversionistas urbanos convertidos en empresarios rurales.

Paradójicamente, la puesta en perspectiva de las mismas fuentes nos revelaba junto a la continuidad y preeminencia de estos muchos y prósperos agricultores el simultáneo surgimiento y progresivo enriquecimiento de un grupo bastante reducido de productores de mayores recursos y de más variadas inversiones, al frente de establecimientos de aparente magnitud y complejidad interna.

Algunos de estos grandes chacareros implementando distintas estrategias (empleo combinado de esclavos, peones y jornaleros primero, arrendamiento, diversificación de cultivos y actividades después) supieron sacar partido de las ventajas derivadas de la ampliación de un mercado para sus trigos y harinas prácticamente cerrado e iniciar, en los primeros años independientes, un proceso de acumulación para nada despreciable que las décadas "proteccionistas" 
del rosismo ${ }^{25}$ y la expansión cerealera de la segunda mitad de siglo no hicieron más que reforzar.

Estos agricultores capitalizados son menos numerosos entre las quintas, orientadas mayormente a la producción forrajera y frutihortícola, aunque algunas de estas explotaciones bien podían ser equiparadas a las de los verdaderos hacendados del partido. Sin embargo, las quintas que más se acercan a las grandes chacras no son, como podríamos suponer, la de aquellos comerciantes o ricos propietarios urbanos que invierten parte de sus capitales en las rentables (y caras) tierras de los alrededores de la ciudad (y para los cuales estas pequeñas explotaciones no representan más que una ínfima parte de sus patrimonios) sino las de productores locales para los que la renta y/o las ganancias directas obtenidas de estos establecimientos constituyen, en casi todos los casos, su única fuente de ingresos.

Así, mientras que entre los más ricos productores es fácil establecer contrastes atendiendo al volumen y a la composición de sus patrimonios (evidentes condicionantes de su capacidad de "negociación" con el mercado), entre los más modestos chacareros y quinteros la situación es la contraria: económica, social y hasta demográficamente estos labradores en muy poco parecen diferenciarse.

Y es que, más allá de las virtuales categorías ocupacionales de los padrones, los pequeños y medianos agricultores de este mundo suburbano conforman un espectro social sumamente heterogéneo, de límites tan cambiantes e imprecisos como los del espacio en el que habitan.

Sabemos que, a medida que avanza el siglo, una agricultura cada vez más comercial y especializada lejos de hacer desaparecer a este grupo de productores multiplica su número y acentúa su ya importante diversidad interna, distanciándolos todavía más del segmento de grandes chacareros y quinteros que, al mismo tiempo, se reduce y consolida.

De esta manera, encontramos que el fortalecimiento de las explotaciones de orientación puramente mercantil y la continuidad, e incluso prosperidad, de la pequeña y mediana producción campesina no constituyen procesos alternativos o excluyentes sino que se presentan como dos realidades funcionalmente articuladas en el abasto de un mercado cuya propia dinámica posibilitaba su coexistencia.

Porque, si bien las amplias fluctuaciones de precios y la ventajosa posición

25-Entre 1821 y 1835 distintas leyes dispusieron varios impuestos de escalas móviles para los cereales y harinas importados e incluso la Ley arancelaria de 1835 prohibió la introducción de granos extranjeros para el abasto de Buenos Aires en el caso de que el precio del trigo local bajara a menos de 50 pesos la fanega. Burgin, M., $1960: 303$. 
de los comerciantes-acopiadores obligaban a muchos de los labradores de Flores a endeudarse $y$, aún en los años buenos, a vender en los peores momentos, una situación de relativa apertura (reflejada en aquella multitud de mercaderes intermediarios al menudeo compitiendo con panaderos y abastecedores urbanos por la producción del hinterland) aseguraba su participación en el aprovisionamiento de la ciudad.

Asimismo, los elevados costos de la mano de obra permitían a pequeños y medianos productores independientes afrontar con éxito la competencia de los más grandes establecimientos cerealeros no solo valorizando el trabajo de su familia sino también convirtiéndose periódicamente en los ocasionales y bien pagos peones de la cosecha y la trilla triguera.

Por otra parte, la oportunidad de emprender con modestas inversiones actividades tan rentables como la venta de forrajes o la fabricación de ladrillos les ayudaba a compensar las perdidas resultantes de un mal año o de una caída repentina de los precios y les proporciona, además de considerables ingresos monetarios, la posibilidad de "ajustar" la producción a una tan diversificada como creciente y variable demanda urbana.

Podemos decir, entonces, que el alto grado de mercantilización de nuestros labradores afirmaba, no sin tensiones y constantes readaptaciones, su presencia y continuidad.

Sin embargo, que algunos de ellos pudieran progresar y convertirse en ricos arrendatarios o pequeños propietarios no debe hacernos olvidar que un mercado imperfecto, inicialmente abierto y fuertemente competitivo generó una diferenciación importante al interior de los sectores sociales involucrados en su abasto, favoreciendo la conformación de un grupo de agricultores económicamente privilegiado que, sin monopolizar la producción, aparentemente de distintas maneras accedía a los mayores beneficios de su comercialización.

Pero si en el desarrollo de las fuerzas del mercado encontramos una de las claves de este juego de permanencias y continuidades, también sabemos que la particular manera en que se desarrolló la dinámica de ocupación, usufructo y apropiación de las tierras del oeste de la ciudad tuvo bastante incidencia en este proceso.

El crecimiento de Buenos Aires estimuló muy tempranamente la puesta en producción de gran parte de las tierras del partido y su posterior traspaso, no siempre mediante procedimientos legales, a manos privadas. Ya en 1828 Senillosa advertía a los para nada desinformados diputados porteños que "Hay tierra de ejido, una legua que parte del Hueco de Lorea, estas tierras se pagaban al Cabildo, después dejaron de cobrarse y luego pasaron a venderse de 
unos en otros poseedores, como si fueran terrenos de propiedad" ${ }^{\prime 26}$.

De este modo, una economía rural en plena expansión sobre las Tierras Nuevas, que recurre, además, a un uso más intensivo de sus recursos acelera la transformación de las antiguas "suertes de chacras de pan llevar" del hinterland más próximo en un espacio de ocupación productiva, de compra y escrituración.

Los padrones y los registros públicos de transacciones nos mostraron que, desde la tercera década del siglo XIX, un grupo cada vez mayor de productores lograba la propiedad plena de no muy extensas superficies de tierra ubicadas entre el ejido y la campaña. Así, mientras que en el sur de la provincia una multitud de modestos labradores-pastores "corría la frontera" ganando tierras al indio, bastante más al norte del Salado, en las mismas puertas de la ciudad muchos otros pequeños y medianos agricultores corrían la frontera de la propiedad ganando tierras al estado.

Y, cuando hacia 1836-40, el gobierno decide vender las tierras públicas otorgadas en enfiteusis, arrendadas o todavía baldías, ellos y no los grandes chacareros o especuladores urbanos serán los principales beneficiarios de la política de "premios y donaciones" implementada por el Restaurador. De hecho, la historia de la fragmentación y venta a sus antiguos arrendatarios de la hacienda de La Chacarita nos dibuja una imagen bastante alejada de la de acaparadores latifundistas y establecimientos improductivos generalmente asociada a los repartos masivos de la época.

El Registro Catastral de la Contribución Directa (1863) no hace más que confirmar la acelerada dinámica de un proceso de apropiación jurídica que ya a mediados de siglo había incorporado a la casi totalidad de las tierras del partido. Propiedades y propietarios de esta lista impositiva adelantan el cuadro que, menos de diez años después, nos pintará el Primer Censo Nacional: pocos grandes y muchos pequeños productores pero, ahora sí, los primeros se perfilan como verdaderos "hacendados terratenientes" concentrando más de la mitad de la superficie total de este Flores de casas quintas y chacras.

De igual manera decíamos que, pese al fortalecimiento de este restringido núcleo, la presencia de propietarios de reducidas parcelas no ha dejado de ser cuantitativamente importante. Por consiguiente, no podemos simplificar los cambios asociados a la transformación del espacio que comienza a operarse con el surgimiento mismo del pueblo, y se proyecta durante las décadas cen-

26-Senillosa parece referirse a la propiedad que Don Diego Flores compró a los herederos de Isidro Lorea, tierras que fueron en parte incorporadas al cuartel del pueblo y el resto fueron luego donadas a la municipalidad de Buenos Aires. Diario de Sesiones, 1828 : 6. 
trales del siglo en la multiplicación de quintas, al fraccionamiento de las extensas suertes dadas en merced al comienzo de nuestra historia de poblamiento.

Seguramente algunas de estas chacras fueron loteadas y vendidas, pero, al menos hasta fines de 1870, lo que encontramos es que la mayoría de los grandes chacareros mantiene intacto e, incluso, acrecienta su patrimonio territorial y que ello no impide que otros más humildes labradores continúen convirtiéndose en propietarios o conserven las quintas que antes compraron o heredaron.

Entonces, las variadas dimensiones, características y valores de las propiedades registradas en el catastro oficial parecen sugerirnos dos evoluciones paralelas, por un lado la concentración de tierras, y probablemente de la producción triguera, en manos de los más ricos agricultores y, por el otro, una atomización relativa que actuando a dos niveles, el de la propiedad y el de la explotación, vincularíamos a las quintas y a la reconversión hortícola.

Paradójicamente, la amplia difusión del arrendamiento reforzó ambos procesos fragmentando internamente en varias unidades de producción las grandes chacras sin disminuir su superficie (a veces hasta aumentándola) y ofreciendo a muchos de los labradores inquilinos de Flores la posibilidad de capitalizarse y acceder a la propiedad de los terrenos que ocupaban.

De hecho, la práctica del arriendo fue funcional a la dinámica de apropiación jurídica de la tierra no sólo transformando a algunos arrendatarios en propietarios sino también permitiendo a chacareros y quinteros extender los límites de sus explotaciones avanzando con sus "colonos" sobre tierras de uso común.

Asimismo, los convenios de arrendamiento e, incluso, los reclamos judiciales entablados por su incumplimiento parecen haber sido para algunos de estos propietarios agricultores la manera de afianzar sus derechos sobre parcelas en conflicto con vecinos interesados en denunciar "sobras" o sobre terrenos cuyas mensuras eran desaprobadas por el Departamento Topográfico ante la inexistencia de títulos que acreditaran la compra.

Porque un contexto de "transición" en el que todavía la noción de propiedad privada y plena coexistía con otras basadas en prácticas y valores consuetudinario $^{27}$ servía de marco a aquella diversidad de propietarios y tipos de propiedad que reflejaba el censo catastral de 1863.

En este caso chacareros y quinteros voluntariamente registrados como contribuyentes parecen haber compatibilizado sus estrategias tendientes a afirmar derechos de propiedad sobre la tierra con las necesidades de un Estado que, en 
proceso de organización, invertía en la elaboración de este verdadero sistema de información. Porque, evidentemente, figurar en las listas públicas de la Contribución Directa era un medio tanto o más efectivo que el cobro de un canon para hacerse reconocer como único propietario de los bienes territoriales declarados.

De este modo, una temprana apropiación legal consolidada a través de distintos mecanismos y complementariamente articulada con la generalización del arriendo de distintas maneras afirmó una estructura de propiedad en la que el crecimiento de los grandes no cuestionaba la permanencia de los pequeños.

Por otra parte, durante todo este tiempo, los cada vez más numerosos vecinos poseedores de títulos de propiedad y productores arrendatarios convivieron con también numerosos ocupantes, provisorios "dueños" de buena parte de las tierras públicas de Flores. Hasta fines del siglo XIX, aún después de la incorporación a la capital, derechos poco claros permitieron la instalación de hecho de las muchas familias agricultoras, quinteros ocasionales y tamberos migrantes que vemos aparecer en los juicios de desalojo de terrenos iniciados por nuevos propietarios apresurados en obtener beneficio de las rentables parcelas que el trabajo de aquellos había contribuido a valorizar. Porque los campos de alfal$\mathrm{fa}$, los potreros de invernada y las quintas de frutas de estos pobladores transformaron en productivos los bajos de los ríos y arroyos que cruzaban el partido, terrenos "supuestamente públicos" que tanto la municipalidad de Flores, y luego de Buenos Aires, como los poseedores de suertes principales reclamaban como de su propiedad.

Así, algunos labradores de escasos recursos, no sabemos cuantos aunque por los litigios y expedientes de mensuras podemos suponer que muchos, haIlaron en las contradicciones normativas del uso de la tierra la posibilidad de acceder a unas pocas cuadras de terreno para emprender algún tipo de producción orientada fundamentalmente al abasto del mercado. Y, al parecer, las ganancias de sus actividades compensaban no sólo las crecidas del río sino también, y sobre todo, lo precario de su situación jurídica y las frecuentes disputas con propietarios tan prevenidos como igual de "expansivos".

Posesión con título legal, arrendamiento en dinero o productos de quinta y simple ocupación, evidentemente son otras las fuentes que nos permitirán analizar la coexistencia de estas diferentes maneras de acceder al usufructo de la tierra, sus posibles articulaciones y/o su sucesión temporal, aspectos que pensamos en el futuro abordar a fin de profundizar el estudio del proceso de construcción y rápida transformación social y productiva de este espacio por demás heterogéneo, el mundo suburbano del abasto. 


\section{Resúmen}

\section{La agricultura a las puertas de la ciudad: arrendatarios, pequeños propietarios y grandes chacareros.}

El presente trabajo forma parte de una investigación mayor centrada en el análisis del proceso de estructuración y desarrollo de los núcleos de crecimiento periurbano más dinámicos de la campaña inmediata a la ciudad de Buenos Aires entre principios del siglo XIX y la década de 1870.

Ocupándonos específicamente del Partido de Flores, pequeño universo de chacras y quintas especializadas en la actividad cerealera/frutihortícola del abasto, buscamos articular las características generales del proceso de poblamiento del oeste porteño con aquellas dinámicas ligadas al uso productivo de las tierras agrícolas geográficamente más cercanas a la capital. Una serie de padrones correspondientes al área realizados entre 1815 y 1869 , testamentarias y listas impositivas constituyen la base documental de nuestro estudio.

\section{Palabras claves}

- Espacio periurbano - Poblacion - Agricultura - Mercado -

\section{Abstract}

\section{"Agriculture at the doors of the city: leaseholders, small owners and big farmers".}

This piece of work forms parte of a major researchbased on the analysis of process of structuring and development of the most dynamic periurban settlements in Buenos Aires surroundings between the early 19th century and the decade of 1870 .

Dealing specifically with Flores District -a tiny universe of small farms orchads specialized in the cereal and horticultural activity in the public market- we seek to articulate the general characteristics of the process of settlement in Western Buenos Aires, with the dynamics linked to the productive use of agricultural land that was closer to the capital city. A series of censuses between 1815 and 1869 corresponding to the area, and executions of wills and tax lists make up the documentary basis for our study.

\section{Key Words}

- Periurban Space - Population - Agriculture - Market - 


\section{Referencias Bibiliograficas}

*BEAUMONT, J.B. (1957), Viajes por Buenos Aires, Entre Ríos y la Banda oriental, 1826-1827, Buenos Aires, Hachette.

*BURGIN, M.(1960), Aspectos económicos del federalismo argentino, Buenos Aires, Hachette, Colección "El pasado argentino".

*CILIBERTO, M. V., (1999) "Los agricultores de Flores, 1815-1838. Labradores "ricos" y labradores "pobres" en torno a la ciudad" en Fradkin, R.; Canedo, C. y J. Mateo (comps.), Tierra, población y relaciones sociales en la campaña bonaerense (siglos XVIII y XIX), Mar del Plata, Editorial de la UNMDP.

*CONI, E. (1927), La verdad sobre la enfiteusis de Rivadavia, Buenos Aires, Universidad de Buenos Aires.

*CONTRIBUCIÓN DIRECTA. Registro Catastral de la Provincia de Buenos Aires (1863), Buenos Aires, Publicación Oficial.

*DIARIO DE SESIONES, $\mathrm{N}^{\circ}$ 109, julio 1828.

*FRADKIN, R. (1992), "Producción y arrendamiento en Buenos Aires del siglo XVIII: la Hacienda de la Chacarita (1779-84)", en Cuadernos de Historia Regional, $N^{\circ} 15$, Luján, UNLu.

$=======$ (1997), "Entre la ley y la práctica: la costumbre en la campaña bonaerense de la primera mitad del siglo XIX", en Anuario IEHS, $N^{\circ} 12$, Tandil, UNICEN.

$=======$ (1999), "Las quintas y el arrendamiento en Buenos Aires (siglos XVIII y XIX)", en Fradkin, R.; Canedo, C. y J. Mateo (comps.), Tierra, población y relaciones sociales en la campaña bonaerense (siglos XVIII y XIX), Mar del Plata, Editorial de la UNMDP.

*GARAVAGLIA, J.C.(1991), "El pan de cada día: el mercado de trigo en Buenos Aires, 1700-1820", en Boletín del Instituto de Historia Argentina y Americana "Dr. E. Ravignani”, $3^{\text {a }}$. Serie, 4, Buenos Aires.

*MAESO, J. Ed. (1855), Registro Estadístico de Buenos Aires, Buenos Aires, Segunda Época.

*MARICHAL, C.(1995), "Liberalismo y política fiscal: la paradoja argentina, 1820-1862", en Anuario IEHS, $N^{\circ} 10$, Tandil, UNICEN.

*MATEO, J. (1994), "Población y producción en un ecosistema agrario de la frontera del Salado (1815-1869)", en Mandrini, R. y A. Reguera (comps.), Huellas en la tierra. Indios, agricultores y hacendados en la pampa bonaerense, Tandil, IEHS.

*PARCHAPPE, N. (1977), Expedición fundadora del fuerte 25 de mayo en Cruz de Guerra. Año 1928, Buenos Aires, Editorial Universitaria de Buenos 
Aires.

*PRIMER CENSO DE LA REPÚBLICA ARGENTINA, verificado los días 15, 16 y 17 de setiembre de 1869, (1872), Buenos Aires. , Imprenta del Porvenir. *SAGUIER, E. (1993), Mercado inmobiliario y estructura social. El Río de la Plata en el siglo XVIII, Buenos Aires, CEAL.

*SANTILLI, D. (1996), "Crecimiento demográfico en Buenos Aires: Quilmes, 1815-1838", Ponencia presentada en las XV Jornadas de Historia Económica, Tandil. 


\section{Anexo cuadros}

Cuadro I: Distribución espacial de las casas, chacras y quintas (San José de Flores, 1836)

\begin{tabular}{|c|c|c|c|c|c|c|c|c|c|}
\hline \multirow{4}{*}{$\begin{array}{l}\text { TIPO DE } \\
\text { UNIDAD } \\
\text { CASAS }\end{array}$} & \multicolumn{9}{|c|}{ CUARTELES } \\
\hline & \multirow{2}{*}{\multicolumn{2}{|c|}{ PUEBLO }} & \multicolumn{2}{|c|}{ SEGUNDO } & \multicolumn{2}{|c|}{ TERCERO } & \multicolumn{2}{|c|}{ QUNNTO } & \multirow{3}{*}{$\begin{array}{c}\text { TOTAL } \\
55\end{array}$} \\
\hline & & & $\mathrm{N}^{\mathrm{o}}$ & & $\mathrm{N}^{\circ}$ & $\%$ & $\mathrm{~N}$ & $\%$ & \\
\hline & 48 & 87,2 & 4 & 7,2 & & & 3 & 5,4 & \\
\hline QUINTA/S & 17 & 10,1 & 57 & 34 & 41 & 24,4 & 53 & 31,5 & 168 \\
\hline $\begin{array}{l}\text { CASA } \\
\text { QUINTA }\end{array}$ & 1 & & & & & & & & 1 \\
\hline CHACRA & 74 & 97,3 & & & 2 & 2,6 & & & 76 \\
\hline $\begin{array}{l}\text { PANADE } \\
\text { RIA }\end{array}$ & 2 & & & & & & & & 2 \\
\hline HORNO & & & & & 1 & & & & 1 \\
\hline ESTANCLA & 1 & & & & & & & & 1 \\
\hline S/ESP. & 149 & 50,5 & 90 & 30,5 & 31 & 10,5 & 25 & 8,5 & 295 \\
\hline TOTAL * & 292 & 47 & 151 & 20,1 & 75 & 14,5 & 81 & 18,4 & 599 \\
\hline
\end{tabular}

Fuente: Censo del Partido de San José de Flores 1836.

* Porcentaje sobre el total de las "propiedades" registradas.

Cuadro II: Distribución de frecuencia del tamaño de las unidades censales (San José de Flores, 1836)

\begin{tabular}{|c|c|c|c|c|c|c|c|c|c|c|c|c|c|c|c|c|c|c|c|c|c|c|c|c|c|}
\hline \multirow[t]{2}{*}{ CUARTEL } & \multicolumn{25}{|c|}{ CANTIDAD DE MIEMBROS } \\
\hline & 1 & 2 & 3 & 4 & 5 & 6 & 7 & 8 & 9 & 10 & 11 & 12 & 13 & 14 & 15 & 16 & 17 & 18 & 20 & 21 & 2526 & 26283 & $32 \quad 33$ & 339 & 4160 \\
\hline PUEBLO & 7 & 17 & 27 & 35 & 30 & 38 & 25 & 32 & 25 & 14 & 11 & 9 & 2 & 5 & 3 & 3 & 2 & 1 & 2 & & 1 & 1 & 1 & 1 & \\
\hline SEGUNDO & 5 & 8 & 24 & 18 & 20 & 12 & 14 & 8 & 14 & 10 & 5 & 5 & 3 & 3 & 1 & 1 & 1 & & & & & & & & \\
\hline TERCERO & & & 9 & 5 & 8 & 11 & 12 & 14 & 2 & 1 & 5 & 2 & 1 & & & 2 & & & & 1 & & & & & 1 \\
\hline QUINTO & 2 & 10 & 5 & 4 & 9 & 8 & 3 & 7 & 5 & 7 & 2 & 3 & 4 & & 2 & & 3 & 1 & 1 & 1 & 1 & & 1 & & \\
\hline TOTAL & 14 & 35 & 65 & 62 & 67 & 70 & 54 & 61 & 46 & 32 & 23 & 19 & 10 & 8 & 6 & 6 & 6 & 2 & 3 & 2 & 11 & 11 & 11 & 1 & 1 \\
\hline
\end{tabular}

Fuente: Censo del Partido de San José de Flores 1836. 
Cuadro III: Inventario de las propiedades de Don Domingo Olivera (San José de Flores, 1866)

\begin{tabular}{|l|c|c|}
\hline PROPIEDADES & PESOS * & $\begin{array}{c}\text { VALOR } \\
\text { REALES }\end{array}$ \\
\hline CASA (BUENOS AIRES) & 7.211 .367 & 48 \\
\hline ESTANCIA (LUJÁN) & 3.166 .493 & 26,6 \\
\hline CAMPO (25 DE MAYO) & 390.000 & 3,2 \\
\hline CAMPO (NECOCHEA) & 158.000 & 1,3 \\
\hline $\begin{array}{l}\text { CHACRA PRINCIPAL } \\
\text { (FLORES) }\end{array}$ & 838.070 & 2 \\
\hline CHACRA (FLORES) & 78.630 & 7 \\
\hline POTRERO (FLORES) & 31.539 & 0,6 \\
\hline POTRERITO (FLORES) & 3.282 & 0,2 \\
\hline TOTAL *** & 11877.381 & 0,02 \\
\hline
\end{tabular}

Fuente: AGN, SUCESIÓN Nº 7295.

* Pesos moneda fuerte.

** Porcentaje sobre el valor total de las propiedades.

*** Falta considerar el ganado (4.000 vacunos, 500 yeguas, 200 caballares y 1.316 ovejas) que en el testamento declara poseer pero que no ha sido valuado ni incluido en ninguno de los inventarios de sus establecimientos productivos.

Cuadro IV: Propiedades y superficies ocupadas (San José de Flores, 1863).

\begin{tabular}{|c|c|c|c|}
\hline \multirow{2}{*}{$\begin{array}{l}\text { TIPODE } \\
\text { PROPIEDAD }\end{array}$} & \multicolumn{2}{|c|}{ TOTAL } & \multirow{2}{*}{$\begin{array}{l}\text { SUPERFICIE EN } \\
\text { HECTAREAS }\end{array}$} \\
\hline & $\mathrm{N}^{\circ}$ & $\%$ & \\
\hline CASA Y QUINTA & 180 & 33,8 & 1573 \\
\hline CHACRA & 97 & 18,2 & $3.889,4$ \\
\hline QUINTA & 14 & 2,6 & 119 \\
\hline $\begin{array}{l}\text { CASAS EN EL } \\
\text { PUEBLO }\end{array}$ & 125 & 23,5 & 46,4 \\
\hline CASA DE CAMPO & 39 & 7,3 & 54,8 \\
\hline RANCHO & 72 & 13,5 & 18,3 \\
\hline HORNO & 1 & 0,1 & 1,7 \\
\hline S/D. & 3 & 0,5 & \\
\hline TOTAL & 531 & 100 & $5.703,8$ \\
\hline
\end{tabular}

Fuente: Contribución Directa. Registro Catastral de la Provincia de Buenos Aires, Publicación Oficial, Buenos Aires, 1863. 
"Plano catastral levantado por el Juez de Paz Martín Farias en 1830 para la Comisión de Solares sobre el trazado por Millan en 1822. Incluido en Cunietti Ferrando, Arnaldo; San José de Flores. Un pueblo a dos leguas de la ciudad; Fundacion Banco de Boston; 1991; pg 24."

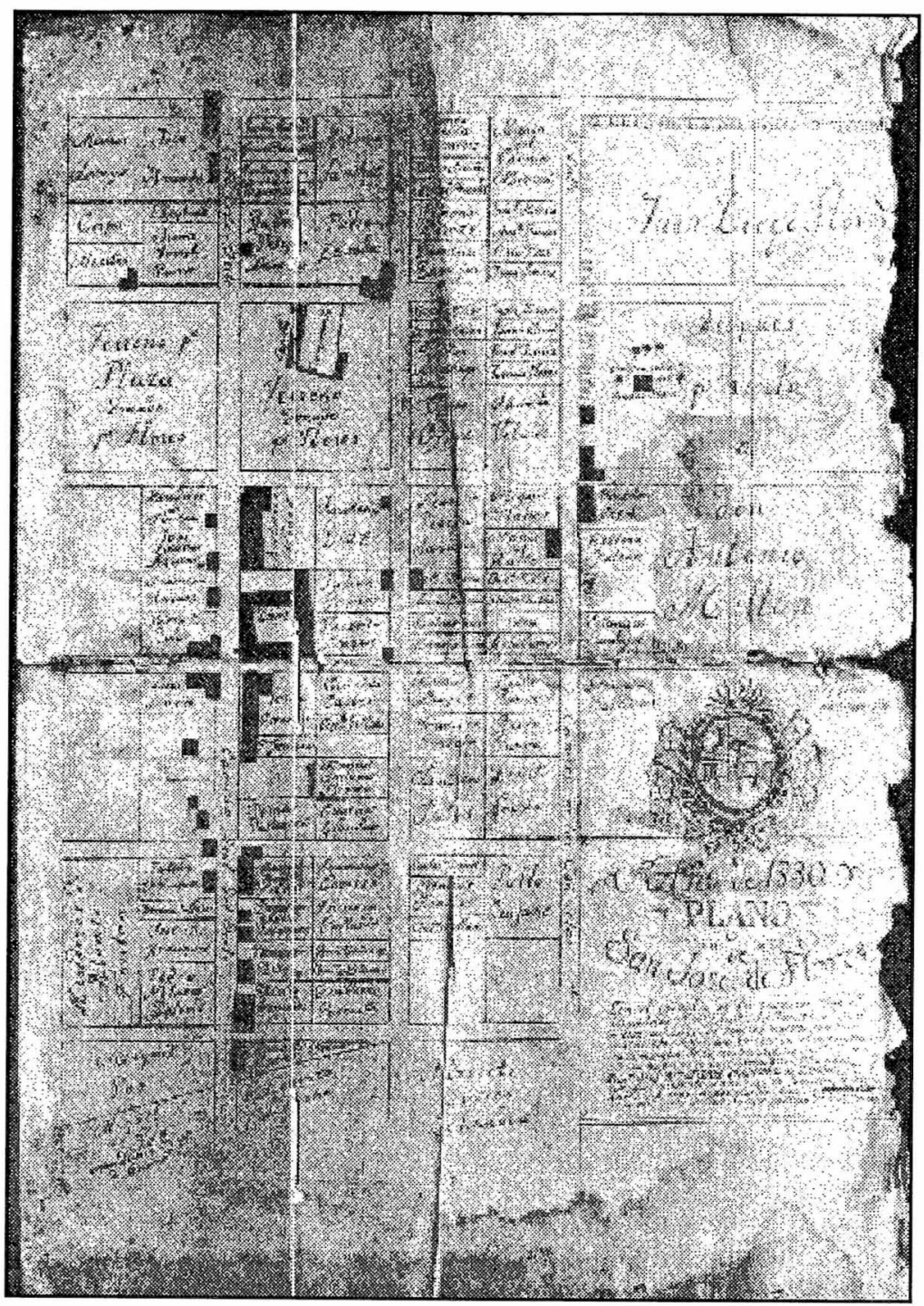

